\title{
PEMANFAATAN ESP8266EX SEBAGAI KONTROL DAYA PENGAMAN MOTOR BERBASIS ANDROID
}

\author{
Anton Breva Yunanda ${ }^{1 *}$, Agung Kridoyono², Mochamad Sidqon ${ }^{3}$ \\ 1,2,3 Teknik Informatika, Universitas 17 Agustus 1945 Surabaya, Surabaya \\ *Corresponding Author \\ E-mail: antonbreva@gmail.com ${ }^{1 *}$, akridoyono@gmail.com ${ }^{2}$, sidqonuntag@gmail.com ${ }^{3}$
}

\begin{abstract}
Abstrak
Alat pengaman motor pada umumnya bersifat manual mekanik menggunakan kunci sebagai pengaktif saklar memiliki kelemahan pada grid kunci sehingga motor masih bisa diaktifkan dengan pemecahan grid. penerapan modifikasi model keamanan bersifat elektrik mekanik menjadikan keamanan ganda dengan menambahkan servo pada motor memiliki supply arus searah memberi tambahan fasilitas keamanan dengan pengaktifan menggunakan transmisi wireless berdaya searah untuk menambah prosedur pengaktifan motor. Maraknya tindakan pencurian kendaraan motor dengan mekanik melalui kunci ini membuat inisiatif bagi penulis untuk merancang sistem kendali berbasis mobile sebagai pengamanan motor untuk melindungi kontaktor starter dari pencurian dengan memanfaatkan switching mekanik untuk pengaktifan sistem starter melalui kendali wireless ESP826.
\end{abstract}

Kata kunci: Pengaman motor, kunci elektrik, ESP8266X.

\begin{abstract}
Motorcycle safety devices are generally manual mechanics using a key as a switch activator which has a weakness in the critical grid so that, The motor can still be activated by breaking the grid. The application of modification of the safety model is electrical and mechanical to make double security by adding a servo to the motor with a direct current supply, giving additional security facilities by activating using a natural power wireless transmission to increase the motor activation procedure. The rise of motor vehicle theft with mechanics through this key has made the author's initiative to design a mobile-based control system as motor security to protect the starter contactor from theft by utilizing mechanical switching for activation of the starter system via the ESP826 wireless control.
\end{abstract}

Keywords: Motorcycle safety, electric lock, ESP8266X.

\section{PENDAHULUAN}

Pada masa sekarang motor memiliki tren daya listrik sebagai sistenya, mulai sistem pengapian pada dynamo start juga mesin semua mengarah pada tren kelistrikan dengan memanfaatan accu sebagai daya utama motor kelebihan sistem ini lebih presisi dan perawatan lebih mudah terlacak factor errornya dengan mudah namun Kelemahan sistem ini membuat ketergantungan terhadap sumber daya listrik sangat tinggi dan dari segi keamanan mudah dilakukan short kontak untuk praktik pencurian.

Berdasarkan kondisi tersebut diperlukan perubahan penambahan alur sistem pengamanan yang sehingga dapat meminimalisir terjadinya tindak pencurian kendaraan bermotor. Oleh karena 
itu pemanfaatan teknologi arduino dengan koneksi wireless ESP8266 [1]. via sistem android yang dipadukan dengan fungsi dari mikrokontroler dari arduino berjenis model arsitektur arduinoESP, Module WIFI untuk operasi aplikasi di perangkat mobile. Arduino dengan tertanam ESP [2] akan sebagai kendali semua berbasis wireless sistem, tombol inputan sebagai aktifasi kerja kendaraan seperti on off start lock semua dikendalikan melalui pengaktifan port di dalam arduino dengan stastus saat interkoneksi wireless terputus maka sistem mengalami gangguan dan menonaktifkan segala kegiatan kelistrikan kendaraan. Pada era listrik digital ini sistem keamanan baru mengarah pada sistem keamanan berbasis computer untuk membuat perlindungan kemanan jalur daya lebih sebagai pengembangan model konvensional sistem mekanik. Untuk membuat model sistem elektrik diperlukan sistem pengatur berbasis mikro yang memiliki IO dan simpan data sebagai proses juga intepreter data serta memanajemen tata unit periperal. Mikrokontrol berupa single chip microcomputer [3] dimana mikrokontroler merupakan system computer dengan tugas yang sangat spesifik seperti arduino.[4] Arduino adalah elektronik board atau kit elektronik open source yang di terdiri chip mikro dengan penstabil tegangan keluaran berupa regulator sebagai produk dari ATMEL.

\section{ArduinoESP}

Arduino berjenis ArduinoESP ini merupakan varian Arduino Compatible Development Board yang memiliki dukungan built in protocol wifi sebagai transmisi data untuk dukungan project berbasis kendali wireless. Arduino biasa yg membutuhkan modul nirkabel External[5][6][7], maka di ArduinoESP menjadi satu didalam terdapat protokol modul wifi berupa chip SoC ESP sehingga ArduinoESP sudah difasilitasi wifi sebagai modul untuk antar muka secara wireless bergelombang radio $2.4 \mathrm{Ghz}$ berprotokol HTTP.

\section{Access Point}

Access point adalah sebuah perangkat perantara atau penyedia transaksional dalam jaringan komputer pada jaringan lokal nirkabel atau WLAN (Wireless Local Area Network). Access point digunakan sebagai penghubung antara ARDUINOESP dengan perangkat mobile seperti android dengan IP yang sudah ditentukan sebgai control [8] perangkat yang terhubung dengan motor.

\section{Relay}

Relay disebut juga switching komponen berjenis elektromik beroperasi melalui sinyal listrik, ketika arus mengalir menuju ke pin relay. Komponen berjenis elektromikanik memiliki bagian utama berupa Elektromagnet coil dan saklar setelah kumparan teraktifasi oleh arus listrik. Prinsip kerja dari komponen berjenis Elektromagnetik pada relay memiliki fungsi mengaktifasi kontak saklar sehingga melalui arus kecil (low power) sebagai aktifator action dapat mengaktifkan kerja arus listrik yang lebih lain dari pin relay yang dikendalikan.

Prinsip kerja Relay dimana Coil dan Contact Coil merupakan kumparan yang dilewati arus, sedang contact adalah berjenis mode saklar yang aktif saat arus lewat di kumparan yang mana terdapat dua operasi yaitu NO kondisi sebelum diaktifkan atau dilalui arus dan NC (awal sebelum aktif close). Sederhananya ketika Coil mendapat arus (energized) lalu timbulah gaya elektromagnet kemudian menarik armature yang berpegas, dan contaktor akan aktif.

\section{Android}

Merupakan salah satu jenis sistem operasi pada perangkat mobile berbasis Linux untuk di desain computer bergerak atau mobile[9] didukung antarmuka layar sentuh untuk operasionalnya 
pada model perangkat handphone ataupun pada layar tab. Android pada beroperasi menggunakan aksi sentuhan seperti ketuk, cubit dan geser dimana aksi ini dari interaksi dengan panel touchscreen. Android juga dikembangkan pada perangkat televisi seperti android tv ataupun model console box seperti STB box, dimana pengoperasiannya bisa terintegrasi dengan TV kabel. Perkembangan android sangat pesat sebanding dengan teknologi perangkat kerasnya seperti processor dan memori sehingga aplikasi yang dihasilkan sangat beraneka ragam seperti jam ataupun kendaraan[10].

\section{METODOLOGI}

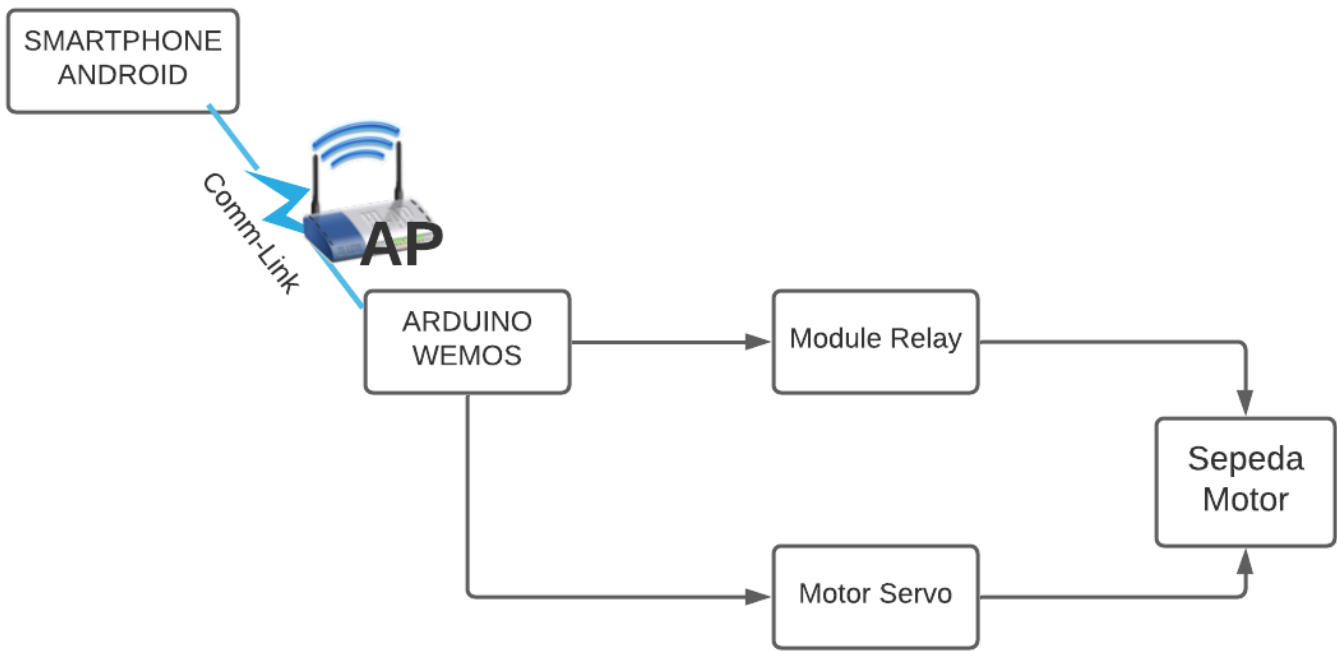

Gambar 1. Blok Diagram sistem kendali berbasis mobile

Pada gambar 1 merupakan blok diagram dimana pusat control dikendalikan menggunakan perangkat mobile android dengan mengacu status serta kendali control dimana arduino sebagai sistem plant aksi kontrolnya sedangkan komunikasinya menggunakan wireless. Mikrokontroller yang sudah builtin ESP melakukan mencari alamat IP dengan AP atau akses point dan android juga melakukan koneksi dengan akses poin untuk diteruskan komunikasinya melalui gelombang wifi sehingga perintah atau command yang dikirim melalui android berbasis protocol komunikasi port 80 dengan destination addressnya menggunakan IP dari MCU arduino tersebut melalui komunikasi peer to peer [11] esp8266mp yang terkoneksi dengan DC servo akan melakukan aksi kontak motor start on off yang terhubung switch motor. 


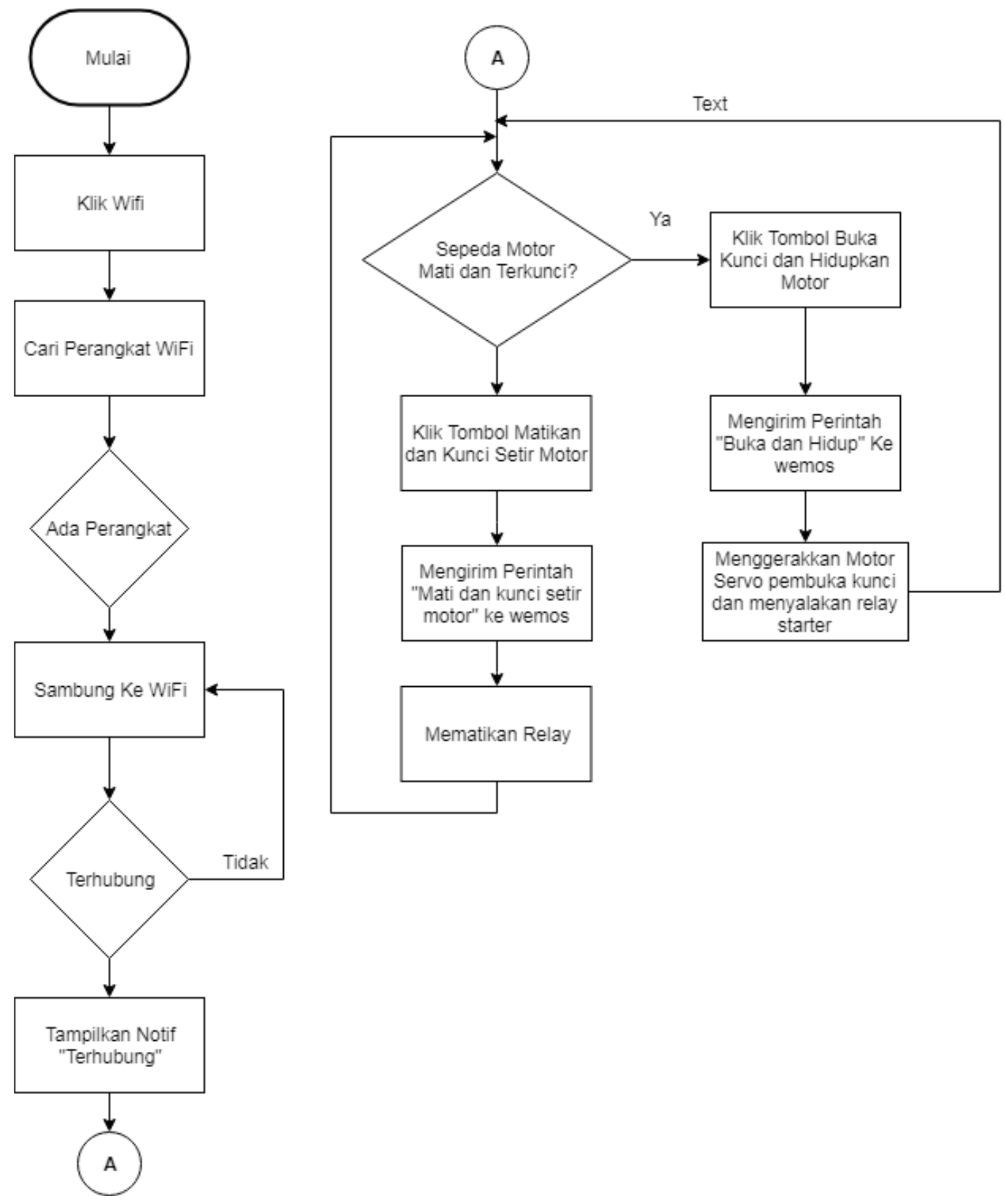

Gambar 2. Flowchart Alur Kerja Sistem

Pertama pada user berupa perangkat Smartphone sebagai pengontrol secara otomatis akan memindai jaringan wifi yang sudah tersedia di akses point dengan melakukan koneksi memasukkan usename dan password sampai terhubung kemudian melanjutkan koneksinya ke arduino esp untuk mengontrol perangkat dengan memasukkan alamat IP arduino. Setelah perangkat wifi connect maka perangkat lunak android akan memindai bagaimana status motor, 
keadaan nyala mati yang sudah tersedia notifnya pada aplikasi android yang semuanya ini tersedia visualisasinya pada perangkat lunak android yang dipegang user.

Proses dengan aksi tersebut dilakukan melalaui aplikasi Smartphone Android selanjutnya eksekusi command untuk proses mati, nyala, buka, kunci pada motor yang berupa bentuk kode dikirim ke Arduino untuk dilakukan aksinya melalui proses output kondisi aksi mati nyala dapat diketahui kondisinya panel label pada android seperti apa perubahan statusnya nyala atau mati.

\section{Skematik alat}

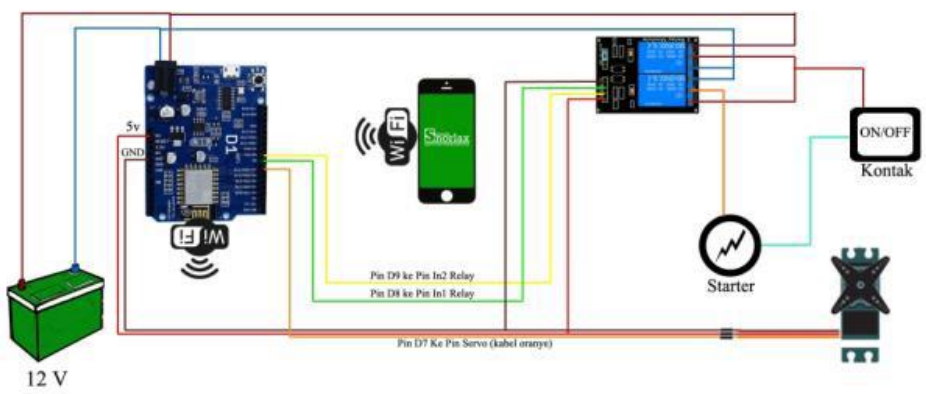

Gambar 3. Skema Alat

Pada gambar 3 supply daya mengambil dari tegangan arus DC kelistrikan motor, fungsi dari tegangan DC ini adalah memberikan catu daya arus listrik pada sistem dimana sistem ini untuk operasi wireless dan arduino yang mana aki ini beroperasi 4 sampai 5ah. Kemudian mikrokontroller bertanam esp8266, dimana merupakan komponen utama yang mengatur jalannya program melalui rangkaian clock $12 \mathrm{mhz}$ yang digunakan untuk mengaktifkan esp, arduino esp merespon request dari client dalam hal ini android yang berkomunikasi mengguaakan komunikasi wireless radio wlan. Kedua komunikasi tersebut dijembatani oleh pihak ketiga dalam hal ini adalah access point sebagai perantara komunikasi berakun yang sudah di set pada client dalam hal ini dan server dalam hal ini mikroESP82 tentunya keduanya harus mengerti username password sebagai pengaman transaksi data pada access point.

Proses transaksional datanya terjadi pada kedua pihak, bisa dimulai pada client android dimana proses yang bisa dilakukan hidupkan dan matikan kendaraan dengan mengakses seperti transaksi TCP web browser bisa juga seperti pada laporan yang dikirim oleh mikrokontroller pada saat status idle pada motor mengalami perubahan yang berada pada proses di pin , 8,9.

Untuk arus kendali yang besar, dikendalikan secara elektromekanik dalam hal ini relay sebagai komponen utama yang dipicu oleh sinyal dari android direquest ke pihak mikrokontroller kemudian di drive sebagai kontaktor untuk arus listrik yang arusnya lebih besar untuk menyambungkan arus yang lebih besar. Pada bagian keluaran atau bagian Output relay Channel pin satu dan dua, terhubung dengan Kontak start On/Off Starter melalui NC relay (Normally Closed) atau posisi awal tertutup.

Konfigurasi operasi kerja Pin Output arduino yang digunakan sebagai berikut :

- Pin 5V : dalam hal ini seperti kode Vcc memberikan muatan proton pada pin relay

- Pin GND : sebagai ground digunakan untuk memberikan muatan electron pada pin

- Pin D8 : sebagai keluaran untuk mengkatif dan nonaktifkan kontak

- Pin D9 : sebagai pin keluaran atau output untuk melakukan aksi starter kontak.

- Pin D7 : sebagai kemuaran ketiga ke inputan servo sebagai buka kunci motor. 


\section{HASIL DAN PEMBAHASAN}

Pada akuisisi data control untuk pengamanan motor dengan arduino berkomunikasi nirkabel ini, dalam melakukan kontrol diimplementasikan ke motor dan proses uji kerja sistem. Pengujian kelancaran meliputi aplikasi perangkat lunak baik pada mikrokontroller maupun program mobile android dan pembangun progem mobilenya serta kendala pada komunikasi serial dan wirelessnya antara mikrokontroller dan android mobile.

Sedangkan pada komunikasi radio wireless, terutama pada penggunaan komunikasi fasilitas pada arduinoESP terhubung komunikasi menggunakan protocol web dan komunikasi radio di frekuensi $2.4 \mathrm{Ghz}$ serta pengamanan layer sessionnya menggunakan usename password yang sudah diintegrasikan pada script pada mikrokontroller disamakan dengan username password pada accessponit sehingga dikenali arsitektur wirelessnya dengan kecepatan baudratenya menggunakan frekuensi 1159200. Berikut merupakan code untuk Konfigurasi WLAN-nya seperti berikut:

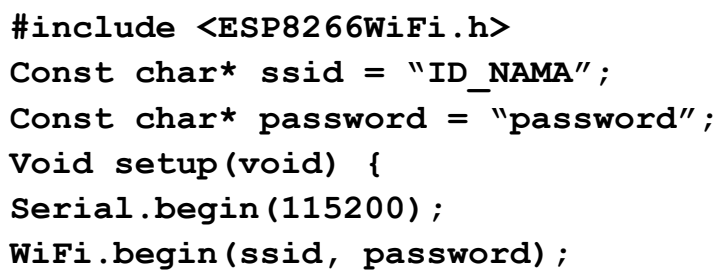

\subsection{Pengujian Aplikasi}

Pada tahap run perangkat lunak android terdapat tombol Button untuk untuk inisialisai kontak ON dan OFF juga Button sebagai aksi buka tutup kunci kendali. Sistem kerjanya ketika tombol kunci dalam kondisi terkunci maka tidak dapat mengakses tombol Kontak ON atau OFF kemudian muncul peringatan "Buka Kuncinya", dengan ini kunci pada stir menjadi terbuka. Ketika kondisi kunci stir sudah terbuka maka bisa mengakses kontak ON atau OFF yang mana ketika aksi klik akan menuju masuk ke halaman kedua dan keluar peringatan "Siap untuk Berkendara??" dan notifikasi pada android "Kontak kunci ON".

Tahap lanjutannya, terdapat dua pilihan tombol. Tombol ON atau OFF dan tombol Starter. tombol starter memiliki fungsi untuk menyalakan kendaraan dan munculkan peringatan "Mesin kondisi nyala" di tampilan aplikasi. Dalam tahapan ini ada kondisi pengamanan saat tombol power tertekan secara tidak sengaja yang dapat membuat mesin menjadi keadaan kondisi matidengan mengeluarkan peringatan kendaraan selesai digunakan atau belum digunakan.

Ketika pada kondisi tombol NO, maka tetap berada pada halaman menu atau menu starter kendaraan, apabila memilih YES maka akan menuju ke halaman kunci stir. Jika back dihalaman kunci stir, maka muncul kondisi peringatan ke pertanyakan kondisi pengendara di saat tersebut berupa peringatan untuk mengunci stir kendaraan sebelum user mengakhiri aplikasi. Apabila stir belum dilakukan penguncian, klik tombol NO maka aplikasinya tidak dapat di close, sampai pada kondisi sudahmenekan yes maka aplikasi bisa tertutup.

\subsection{Pengujian Kontak dengan Relay}

Pada rangkaian switching menggunakan relay yang menggunakan supply input dari arduinoESP sebagai sumber tegangan masukan pada modul relay sebesar area kerja 5vDC, keluaran atau output pada asumsi supply tegangan $12 \mathrm{v}$ yang mana $12 \mathrm{vdc}$ tersebut bearasal dari 
Aki kendaraan. ketika modul relay kontak diaktifkan akan memberikan output daya ke relay 2 atau starter.

Uji sistem perangkat lunak pada aplikasi di android seperti tombol start akan mengirimkan sinyal atau perintah ke arduino melalui wifi dan diolah sehingga arduino mengirim sebuah perintah ke relay untuk mengeksekusi dalam menghidupkan kendaraan.

\subsection{Pengujian Program}

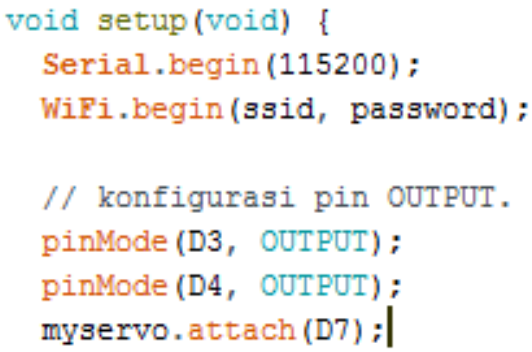

ArduinoESP memiliki sejumlah 11 pin yang digunakan sebagai IO pin input atau output, Pada system ini IO pin yang dimanfaatkan tiga yang mana semuanya digunakan sebgai outputan sistem. Sedangkan pembuatan perangkat lunak mobile androidnya menggunakan android studio.

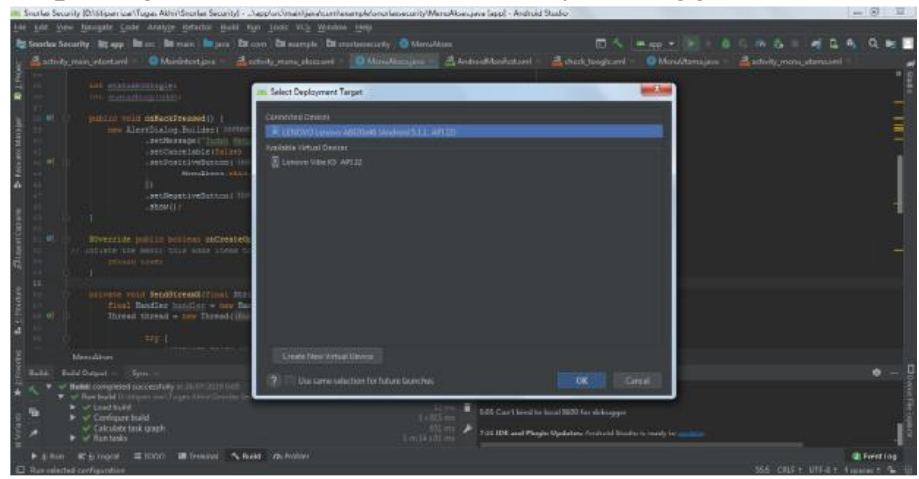

Gambar 4. Android Studio

Proses kerja app pada android studio berupa compiler bahasa java android studio melalui perintah dikirim ke bentuk bahasa mobile program arduino agar dapat dibaca dan di lakukan eksekusi, cara me_running app di android studio melalui aksi klik di icon play pada menu atas bisa juga dengan tombol gabung Shift+F10, kemudian pilih mode perangkat bergerak dalam hal ini smartphone di menu "connected device" dan klik label OK,proses selanjutnya gradle running dan indexing apk kemudian intalling apk lalu selesai. Apabila berhasil maka aplikasi otomatis menjadi terbuka di smartphone apabila tidak dalam event kesalahan atau error.

\section{KESIMPULAN}

Dari hasil system yang diuji melalui pengukuran dan analisis, maka terdapat beberapa kesimpulan antara lain: peragkat bekerja normal, tetapi terdapat beberapa kesalahan seperti uji respon di tombol perangkat lunak mobilenya seperti saat diklik ataupun eksekusi perintah pada arduino, terdapat delay 3-4 detik atau kadang tidak ada response. Perangkat ini membutuhkan daya diatas $4.5 \mathrm{~A}$ sehingga hanya kendaraan berkapasitas $125 \mathrm{cc}$ dari pabrikan atau penggantian Accu untuk kendaraan dibawah 125CC. kondisi operasi tidak bisa bertahan dayanya secara baik pada motor kondisi mati selama 10hari karena terkuras dengan daya secara kontinyu. 


\section{DAFTAR PUSTAKA}

[1] M. Mehta, "ESP 8266: a breakthrough in wireless sensor networks and internet of things," Int. J. Electron. Commun. Eng. I\& Technol., vol. 6, no. 8, pp. 7-11, 2015.

[2] H. Yuliansyah, "Uji Kinerja Pengiriman Data Secara Wireless Menggunakan Modul ESP8266 Berbasis Rest Architecture," Electrician, vol. 10, no. 2, pp. 68-77, 2016.

[3] A. N. N. Chamim, "Penggunaan microcontroller sebagai pendeteksi posisi dengan menggunakan sinyal GSM,” J. Inform., vol. 4, no. 1, pp. 430-439, 2010.

[4] D. Pratama, D. A. Hakim, Y. Prasetya, N. R. Febriandika, M. Trijati, and U. Fadlilah, "Rancang Bangun Alat dan Aplikasi untuk Para Penyandang Tunanetra Berbasis Smartphone Android," Khazanah Inform. J. Ilmu Komput. dan Inform., vol. 2, no. 1, pp. 14-19, 2016.

[5] T. Tarmuji, "Perancangan dan pembuatan alat pengukur getaran mekanis menggunakan piezzo electric sensor berbasis arduino mikrokontroller," Emit. J. Tek. Elektro, vol. 15, no. 2, pp. 53-59, 2015.

[6] H. Supriyono and A. D. N. Setyawan, "Perancangan Immobilizer Berbasis RFID untuk Sepeda Motor," Emit. J. Tek. Elektro, vol. 16, no. 2, pp. 69-73, 2016.

[7] S. M. Chaware, S. Dighe, A. Joshi, N. Bajare, and R. Korke, "IJIREEICE IJIREEICE Smart Garbage Monitoring System using Internet of Things (IOT)," Int. J. Innov. Res. Electr. Electron. Instrum. Control Eng. ISO, vol. 3297, no. 1, pp. 2321-5526, 2007, doi: 10.17148/IJIREEICE.2017.5115.

[8] A. A. Alamsyah and M. N. Faisal, "Perancangan Dan Penerapan Sistem Kontrol Peralatan Elektronik Jarak Jauh Berbasis Web,” J. Mek., vol. 6, no. 2, pp. 577-584, 2015.

[9] N. Safaat, "Android; Pemrograman Aplikasi Mobile Smartphone dan Tablet PC Berbasis Android," 2012.

[10] F. R. Doni and T. Widianto, "Rancangan Pengaman Sepeda Motor Berbasis Mikrokontroler Atmega16 Dengan Kontrol Android," J. Evolusi, vol. 3, no. 1, 2015.

[11] S. Tharishny, S. Selvan, P. Nair, and others, "Android based smart house control via wireless communication,” Int. J. Sci. Eng. Technol., vol. 5, no. 5, pp. 323-325, 2016. 